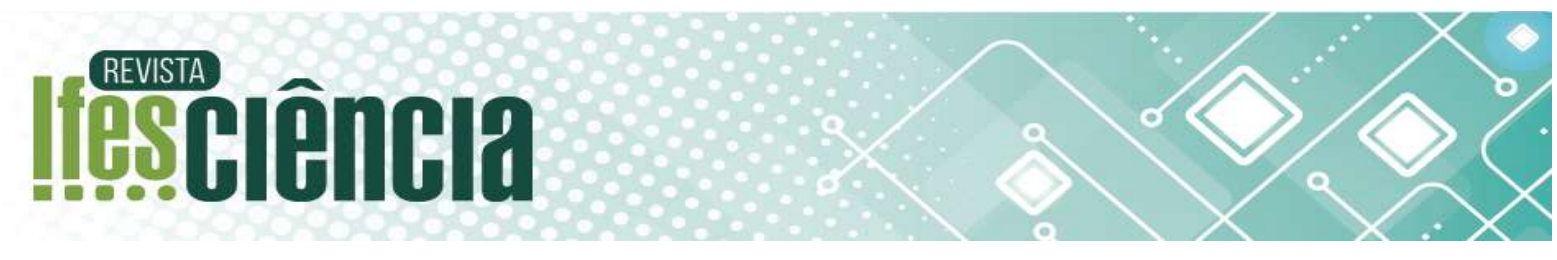

\title{
MANIFESTAÇÕES PATOLÓGICAS CAUSADAS POR SISTEMAS DE CLIMATIZAÇÃO NO IFES CAMPUS VITÓRIA
}

\author{
PATHOLOGICAL MANIFESTATIONS CAUSED BY AIR CONDITIONING \\ SYSTEMS AT IFES CAMPUS VITÓRIA
}

\author{
${ }^{1}$ Gercyr Baptista Junior* \\ ${ }^{2}$ Leila Celin Nascimento \\ ${ }^{3}$ Gabrieli Ferreira dos Santos

\begin{abstract}
${ }^{1}$ Instituto Federal do Espírito Santo. E-mail: (gercyr@ifes.edu.br). ${ }^{2}$ Instituto Federal do Espírito Santo. E-mail: (leilacelin@ifes.edu.br). ${ }^{3}$ Instituto Federal do Espírito Santo. E-mail: (gabrielifesantos@gmail.com).

*Autor de correspondência
\end{abstract}

Artigo submetido em 15/12/2020, aceito em 23/03/2021 e publicado em 05/05/2021.

Resumo: A umidade é uma grande causadora de manifestações patológicas e acarreta a degradação das construções. O sistema de climatização é uma das fontes desta água indesejada nas edificações e uma manutenção periódica desses sistemas e das edificações são primordiais para prevenir esses problemas. Em edificações antigas, em que o sistema de climatização não foi projetado, mas que os aparelhos foram sendo instalados sem projeto adequado ao longo do tempo, há uma tendência de agravamento das manifestações patológicas. Este é o caso das edificações do Ifes, Campus Vitória, que possui prédios inaugurados na década de 1940, tendo uma quantidade relevante de problemas junto aos aparelhos de ar-condicionado. Objetivou-se com este trabalho identificar se as manifestações patológicas localizadas nas proximidades dos aparelhos de ar-condicionados da edificação do Ifes, Campus Vitória, são efetivamente originárias desses aparelhos. A metodologia adotada foi mapear os aparelhos de climatização, avaliar o grau das anomalias patológicas e agrupar as manifestações patológicas em conjuntos. Constatou-se que $97(45,33 \%)$ dos 214 equipamentos estão ocasionando problemas de manifestações patológicas nos edifícios, afetando consideravelmente boa parte das dependências, demandando intervenções reparadoras e eliminação de suas causas para assegurar uma melhor durabilidade, funcionalidade, habitabilidade e estética da instituição.

Palavras-chave: ar-condicionado; patologia das construções; umidade em edificações.

Abstract: Moisture is a major cause of pathological manifestations and it causes the degradation of buildings. The air conditioning system is one of the sources of this unwanted water in buildings and periodic maintenance of these systems and buildings are essential to prevent these problems. In old buildings, where the air conditioning system was not projected, but where the air conditioners were being installed without an adequate project over time, there is a tendency for the pathological manifestations to worsen. This is the case of Ifes' buildings, at Vitória Campus, where there are buildings that were inaugurated in 1940's, having a lot of problems with air conditioners. The objective of this study is to identify if the pathological manifestations located close to air conditioners of Ifes' building, Campus Vitória, are actually from these air conditioners. The methodology adopted was to map the air conditioners, to assess the level of these pathological manifestations and group the 
pathological manifestations in sets. It was found that 97 (45,33\%) of the 214 equipment are causing problems with pathological manifestations in the buildings, affecting considerably a large part of the premises, requiring repair interventions and eliminating their causes to ensure a better durability, functionality, habitability and aesthetics of the institution.

Keywords: air conditioning; construction pathology; moisture in buildings.

\section{INTRODUÇÃO}

As manifestações patológicas, no âmbito da engenharia, referem-se à degradação da edificação e aos problemas gerados em função delas. É importante ressaltar que o termo se difere de patologia, que é a ciência que estuda essas manifestações patológicas e suas origens. Essas anomalias podem agir sobre as edificações causando danos e influenciando na sua vida útil, uma vez que afeta a sua qualidade e a sua aparência (FRANÇA et al., 2011).

Segundo Souza e Ripper (1998), as causas podem ser classificadas em dois tipos: as intrínsecas, quando o fato gerador é da própria edificação, ou seja, está ligado ao processo de deterioração que vão desde os materiais utilizados na fase de execução até a sua utilização; e as extrínsecas, que ocorrem quando os agentes são externos, como por exemplo, a umidade.

De acordo com Ayuso et al. (2016), as anomalias ou defeitos nas fachadas dos edifícios resultam de uma combinação de causas e fatores agressivos, que geralmente ocorrem de forma simultânea, levando à perda de desempenho ao longo do tempo.

$\mathrm{O}$ Instituto Brasileiro de Desenvolvimento da Arquitetura (IBDA), (2015, apud OLIVEIRA et al., 2016) diz que a umidade pode trazer desde danos simples até comprometimentos sérios a estrutura, bem como impactar as pessoas que utilizam esse local.

Dentre as causas que são originadas por agentes de deterioração estão as instalações de ar-condicionados. A manifestação patológica pode ocorrer quando os aparelhos são fixados, depois que a obra foi finalizada ou quando são colocados em lugares sujeitos a prejudicar a pintura, revestimento e tubulações. A estrutura da edificação deve propiciar uma drenagem efetiva para evitar acúmulo de água nos elementos construtivos (OLIVEIRA et al., 2020).

Quando uma edificação é construída, o que se espera é que ela tenha uma vida útil relativamente longa, de no mínimo: 50 anos para a estrutura, 40 anos para a vedação externa e 20 anos para a vedação interna, de acordo com a NBR 15575 (2013). Todavia, o que se percebe na prática é que, costumeiramente, problemas começam a surgir bem antes desse período estimado. E quando isso ocorre, os transtornos são inúmeros até pelo fato de a edificação já estar em uso, o que traz desafios para a sua recuperação (SACHS, 2015).

Conforme Ferreira (2020), em construções mais antigas os problemas tendem a ser mais graves, devido à idade $\mathrm{e}$ ao maior tempo a que estão sujeitas a agentes de degradação.

Quando o problema acontece, é necessário analisar o que está ocorrendo, identificar o motivo que levou ao surgimento da manifestação patológica para saber quais medidas devem ser adotadas para a sua recuperação, buscando-se evitar que outras ocorram. Há anomalias que podem não ser notadas, devido ao fato de estarem escondidas, quando é camuflada por outra ou quando não aparecem de forma clara. Assim, resultados mais fiéis exigem uma análise mais profunda de todo contexto envolvido, diz Vissotto (2015, apud SACHS, 2015).

Várias são as manifestações patológicas que podem ser encontradas nas edificações. Dentre elas estão as fissuras, 
que se formam por retração na argamassa ou excesso de desempenamento (CORSINI, 2010); o lodo que é a formação de microrganismos (MARTINS et al., 2020) e as manchas, que surgem devido a absorção de água pelo substrato (FREITAS et al., 2020). Também é bem comum o aparecimento de mofo que se dá pela proliferação de fungos em locais úmidos, quentes e mal iluminados, formando manchas escuras (SILVA, 2020), bem como as bolhas que são estufamentos na superfície (AMORETTI et al., 2020).

Outras anomalias são a abrasão, cujos fatores causadores mais comuns são o ar e a água, pois transportam partículas, gerando erosão (BEZERRA, 2020); o descascamento, que ocorre devido à ausência de aderência da superfície com o substrato (FREITAS et al., 2020). Segundo Oliveira et al. (2016), também podem ser citadas a saponificação, que se manifesta com o surgimento de manchas, gerando destacamento e degradação ou pela presença da alcalinidade no substrato.

Segundo Pereira et al. (2020), a partir de inspeções prediais é possível a criação de uma lista de classificação de defeitos nas edificações, na qual cada defeito é identificado durante a vistoria.

Deve-se incluir informações sobre tecnologia de construção para fornecer orientação sobre questões associadas à construção e ao projeto. A lista de classificação de defeitos deve ser diferenciada de uma lista de classificação de causas das manifestações patológicas (PEREIRA et al., 2020).

Com este artigo, propõe-se abordar, especificamente, a manifestação patológica causada pela umidade oriunda de aparelhos de climatização, usando como local de pesquisa o IFES, Campus Vitória, por ser uma unidade com um número significativo desses aparelhos e percebendo haver nela a existência do fato a ser estudado.

De acordo com Sueth et al. (2009), a edificação estudada foi inaugurada em 11 de dezembro de 1942 e não foi planejada para receber sistema de climatização. $\mathrm{O}$ projeto original não possui as instalações necessárias do sistema, tais como drenagem dos aparelhos, o que pode ocasionar problemas que têm como consequência o surgimento de infiltração.

O objetivo deste trabalho é identificar se as manifestações patológicas localizadas nas proximidades dos aparelhos de ar-condicionados da edificação do IFES, Campus Vitória, são efetivamente originárias desses aparelhos. Os objetivos específicos são: mapear os aparelhos de climatização, avaliar o grau das manifestações patológicas e agrupá-las em conjuntos.

\section{METODOLOGIA}

\subsection{MÉTODO}

O primeiro passo foi escolher uma edificação para o estudo e obter o projeto arquitetônico, para localizar os equipamentos de climatização em projeto. Em seguida, realizou-se uma vistoria no local, a fim de identificar anomalias, registrá-las e analisá-las.

Após identificar cada aparelho, criou-se uma legenda específica conforme os tipos dos aparelhos de climatização existentes ("de janela" ou "split"), conforme apresentado no quadro 1 a seguir, e posteriormente localizá-los em planta baixa, mapeando-os.

Quadro 1: Legenda para identificar os modelos dos aparelhos de climatização.

\begin{tabular}{|c|c|c|}
\hline \multicolumn{2}{|c|}{ Tipo de aparelho } & Símbolo \\
\hline \multicolumn{2}{|c|}{ De janela } & \\
\hline \multirow[t]{2}{*}{ Split } & Condensadora & \\
\hline & Evaporadora & \\
\hline
\end{tabular}


Depois de localizar os aparelhos, foi elaborada uma união das manifestações patológicas encontradas. $\mathrm{O}$ grupo de manifestações patológicas que se repetiram foi listado e identificado com uma numeração, que corresponde ao tipo de anomalia identificada, conforme quadro 2 , a seguir.

Quadro 2: União das manifestações patológicas detectadas incomum

\begin{tabular}{|c|c|}
\hline Tipo & Manifestações patológicas \\
\hline 1 & Manchas, bolhas. \\
\hline 2 & $\begin{array}{l}\text { Manchas, lodo, abrasão, empoçamento, } \\
\text { bolhas. }\end{array}$ \\
\hline 3 & Manchas, lodo, empoçamento, abrasão. \\
\hline 4 & $\begin{array}{l}\text { Manchas, bolhas, lodo, empoçamento, } \\
\text { abrasão, descascamento. }\end{array}$ \\
\hline 5 & $\begin{array}{l}\text { Manchas, bolhas, empoçamento, } \\
\text { abrasão. }\end{array}$ \\
\hline 6 & $\begin{array}{l}\text { Manchas, lodo, descascamento, } \\
\text { empoçamento, abrasão, fissura, } \\
\text { saponificação, bolhas. }\end{array}$ \\
\hline 7 & Manchas, lodo. \\
\hline 8 & $\begin{array}{l}\text { Manchas, lodo, descascamento, } \\
\text { empoçamento, abrasão, saponificação, } \\
\text { bolhas. }\end{array}$ \\
\hline 9 & $\begin{array}{l}\text { Manchas, lodo, abrasão, } \\
\text { descascamento, empoçamento. }\end{array}$ \\
\hline 10 & Manchas, abrasão. \\
\hline 11 & Manchas, abrasão, lodo. \\
\hline 12 & Empoçamento, abrasão. \\
\hline 13 & Manchas, bolhas, abrasão, lodo. \\
\hline 14 & $\begin{array}{l}\text { Empoçamento, manchas, bolhas, } \\
\text { descascamento. }\end{array}$ \\
\hline 15 & Manchas, bolhas, descascamento. \\
\hline 16 & $\begin{array}{l}\text { Manchas, lodo, empoçamento, abrasão, } \\
\text { bolhas, fissura. }\end{array}$ \\
\hline 17 & Bolhas. \\
\hline 18 & Abrasão. \\
\hline
\end{tabular}

Fonte: Autor.

Posteriormente, foi executada a avaliação do grau de degradação das manifestações patológicas, podendo ser classificado em 3 tipos: alto, médio e baixo. O critério utilizado foi verificar o local que estava sendo afetado, considerando-se alto onde a umidade afetou a parede da edificação, médio quando atingiu os pisos internos e baixo quando prejudicou os pisos externos.

\subsection{VISTORIA}

Foram realizadas visitas no campus no período compreendido entre julho de 2019 a fevereiro de 2020, nos turnos matutino e vespertino. Registrou-se fotos dos aparelhos de metade das edificações do Ifes, Campus Vitória (identificados em projeto como sendo os blocos B, C, D, E, G, $\mathrm{Q}, \mathrm{R}, \mathrm{S}, \mathrm{V}, \mathrm{Y}$, conforme a figura 1), e depois estes foram localizados em planta, indicando-se o modelo do aparelho e as manifestações patológicas apresentadas através do uso de simbologias.

Figura 1: Ifes - Campus Vitória

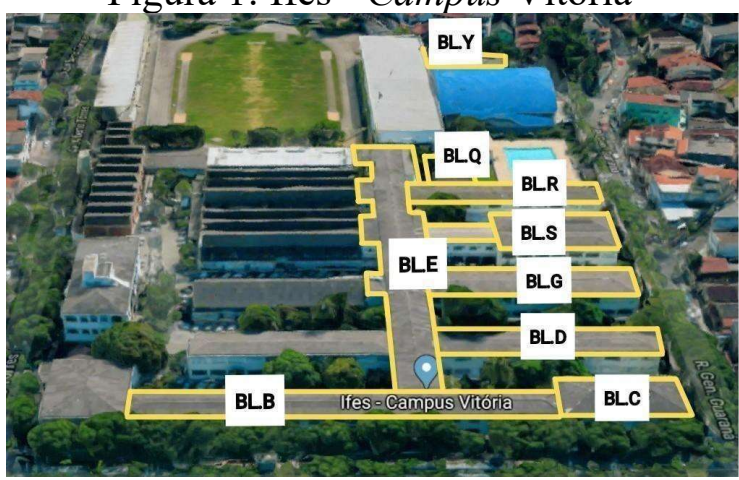

Fonte: Google Maps. (Acesso em jul. 2020). (Adaptada pelo autor).

Foi realizada uma análise, por meio das fotografias, para a descrição das manifestações patológicas presentes e para posteriormente serem utilizadas para um diagnóstico mais completo. Nessa fase, foi observado se havia ou não a presença de manchas, fissuras, desplacamento, empoçamento, mofo, limo, abrasão, corrosão de armadura, eflorescência, empolamento, descascamento ou outro tipo de problema. 


\subsection{ANAMNESE}

A edificação analisada pertence ao Instituto Federal do Espírito Santo (Ifes), Campus Vitória, localizado em Jucutuquara, Av. Vitória, no município de Vitória, Espírito Santo. A estrutura desta edificação foi construída em dezembro de 1942, possuindo 78 anos, e ocupa uma área construída de 25.905,87 $\mathrm{m}^{2}$. A área escolhida para estudo e análise corresponde a $12.262,65 \mathrm{~m}^{2}$.

Figura 2: Fachada principal do Ifes na década de 1930/1940

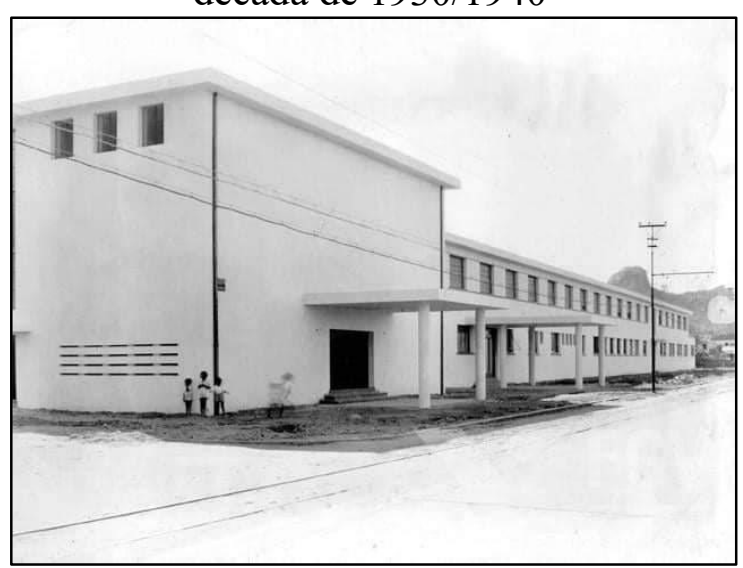

Fonte: FGV/CPDOC ([20--?] apud VEDOVA, 2020). (Acesso em nov. 2020).

Figura 3: Fachada principal em 2019

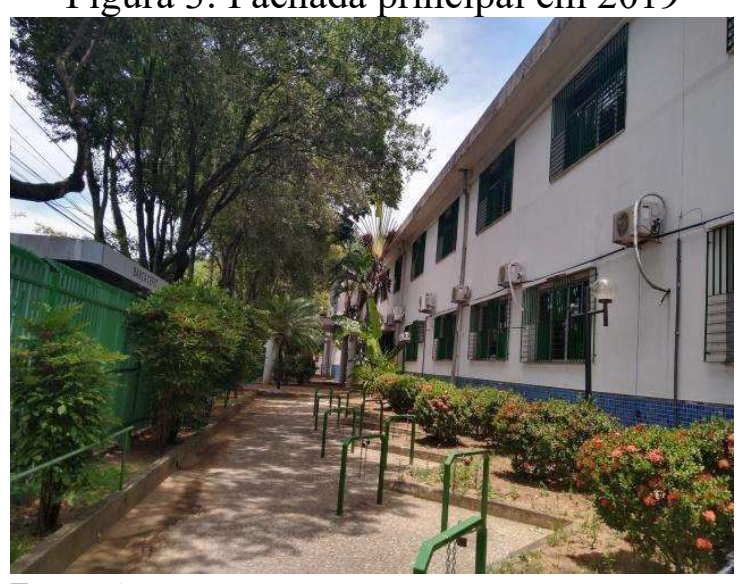

Fonte: Autor.
Figura 4: área interna do Ifes na década de 1940.

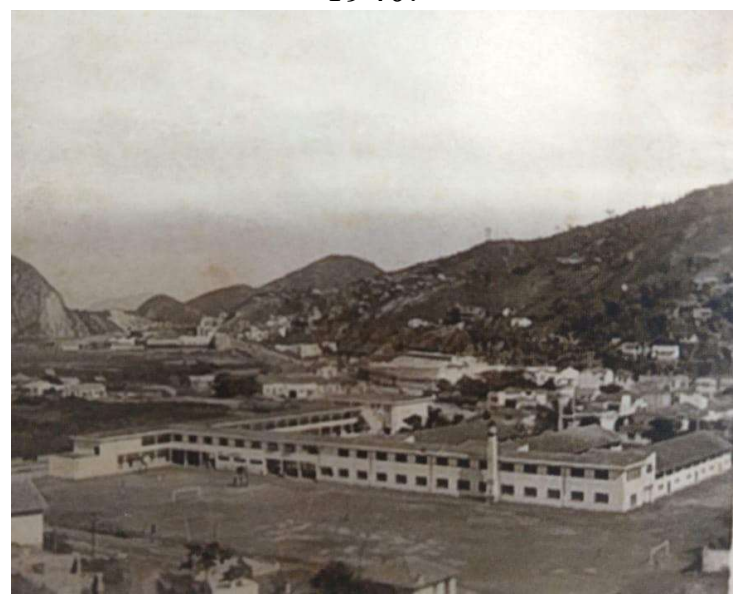

Fonte: Sueth et al (2009, p. 56)

Figura 5: Área interna no ano de 2020

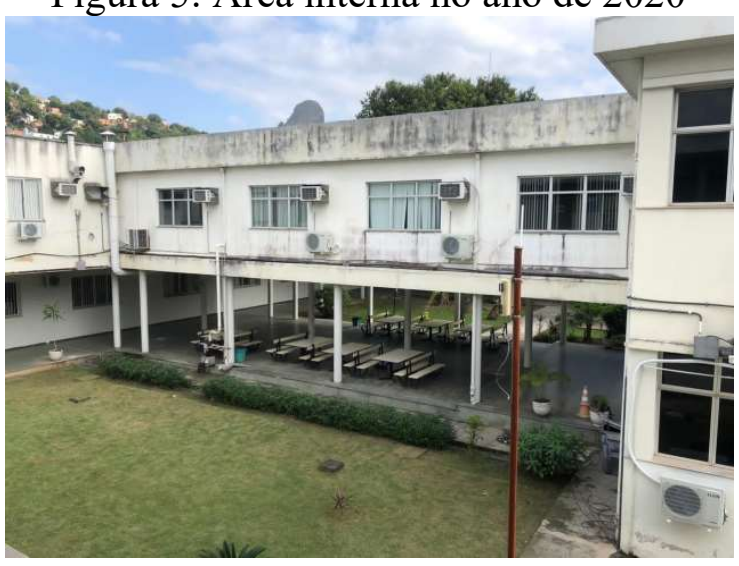

Fonte: Autor.

$\mathrm{Na}$ figura 2 é possível notar que ainda não haviam equipamentos de climatização e na figura 3 observa-se a presença dos aparelhos. Na figura 4 também se observa que a área interna não possuía arcondicionados, já na figura 5, pode-se verificar a presença deles internamente. Essas observações apontam que a edificação não foi projetada para a instalação futura de sistema de climatização. 
Portanto, os aparelhos foram instalados sem o devido planejamento, pois não constavam no projeto inicial da obra, o que favorece o aparecimento de manifestações patológicas. Destaca-se que a própria característica dos equipamentos de climatização instalados leva a entender que não houve um projeto de climatização e, consequentemente, compatibilização entre os sistemas.

A edificação é dividida em blocos com sistema estrutural convencional em concreto armado, de 2 pavimentos. Os componentes de vedação são em alvenaria de tijolos cerâmicos e as coberturas são embutidas com platibandas.

\section{RESULTADOS E DISCUSSÃO}

Neste tópico estão apresentados e discutidos os resultados das vistorias realizadas nos blocos. De acordo com as análises feitas nas vistorias, as manifestações patológicas encontradas foram: abrasão, lodo, descascamento, fissura, manchas, empoçamento, empolamento e saponificação.

\subsection{MANIFESTAÇÕES PATOLÓGICAS ENCONTRADAS}

A seguir, encontram-se os resultados e discussões de cada bloco onde foram encontradas as manifestações patológicas.

Através das imagens a seguir é possível reconhecer $\mathrm{o}$ estágio de degradação da edificação em função da umidade originada dos ar-condicionados. Foram selecionados os registros dos piores casos de cada tipo de anomalia do 1 ao 5, que são os frequentes.
Figura 7: Laboratório de ensaio de materiais não destrutivos, $1^{\circ}$ pavimento do bloco E. (a): Vista frontal, (b): Detalhe

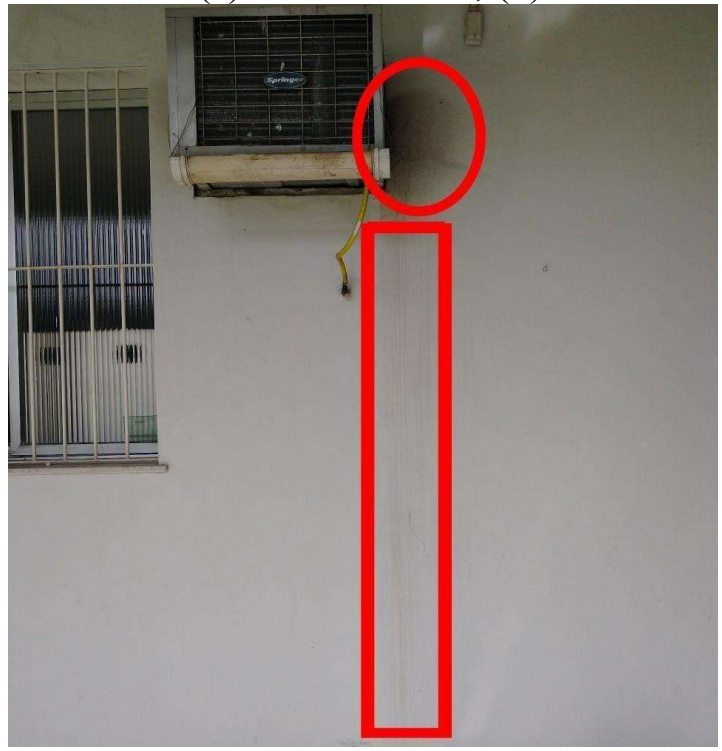

Fonte: Autor.

(a)

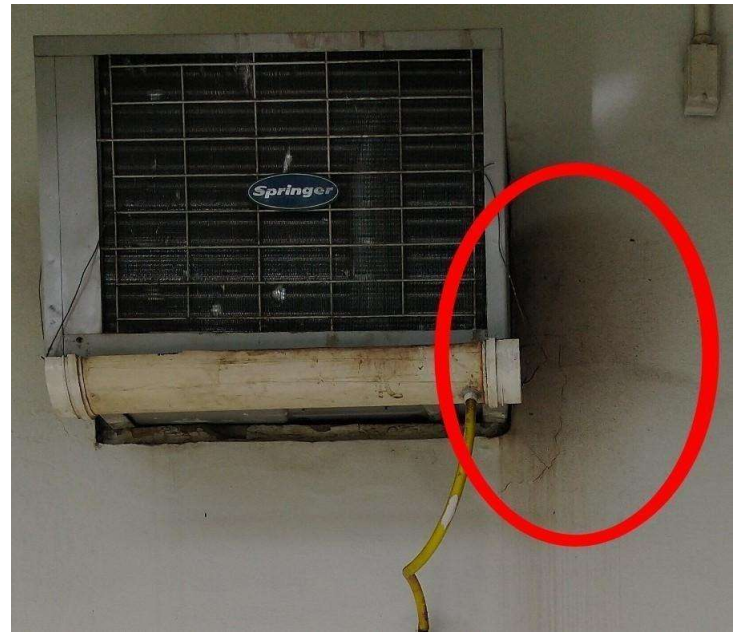

Fonte: Autor.

(b)

Os problemas são de grau alto e tipo 1: manchas e bolhas. A água do aparelho infiltrou na parede ficando acumulada, levando o surgimento de bolhas $\mathrm{e}$, consequentemente, de manchas. $\mathrm{O}$ dano maior foi do lado direito (figura 7b). Há também uma pequena listra de bolhas e manchas no formato vertical, como mostra a (figura 7a). 
Figura 8: Fachada da sala de coordenação de química e biologia, no bloco G. (a):

Vista frontal, (b): Detalhe

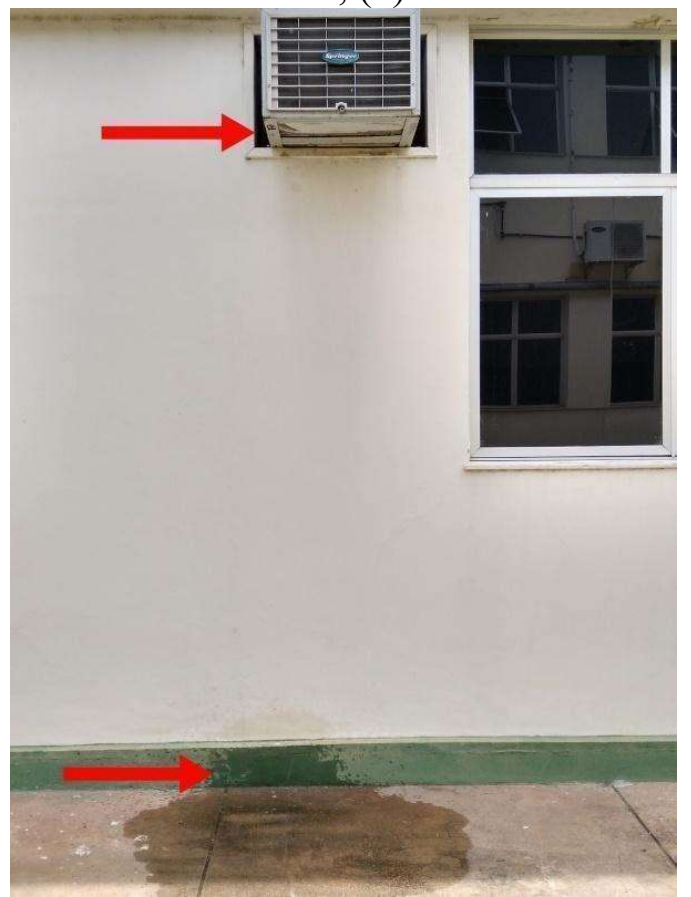

Fonte: Autor.

(a)

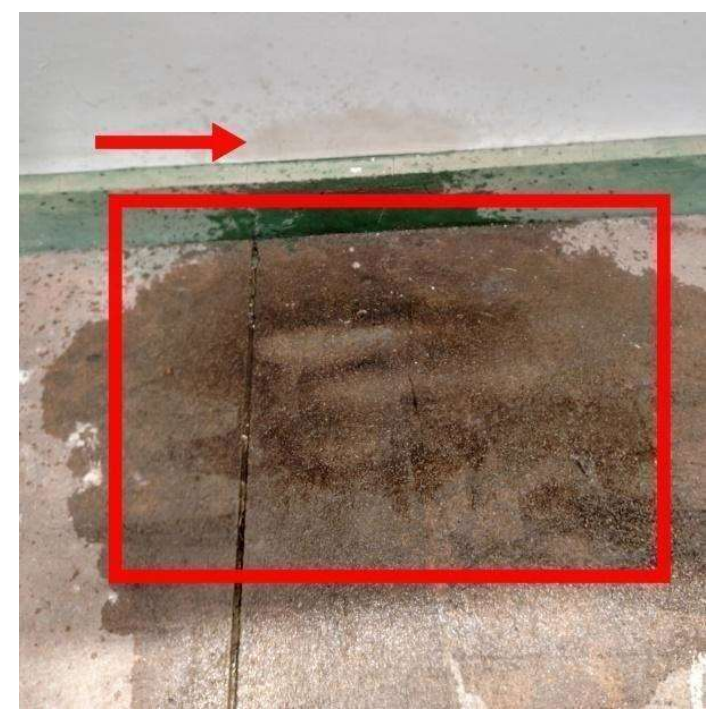

Fonte: Autor.

(b)

Caracteriza-se grau alto e tipo 2: manchas, lodo, abrasão, empoçamento, bolhas. Não possui sistema de drenagem (figura 8a). Desse modo, a água cai diretamente na calçada, ocasionando uma leve abrasão, empoçamento e formação de lodo (manchas escuras mostradas no detalhe, figura 8b). O líquido bate no chão e respinga na parede (como aponta a seta do detalhe), gerando manchas e bolhas pelo acúmulo de água no substrato.

Figura 9: $1^{\circ}$ e $2^{\circ}$ aparelhos do lado direito do salão de estudos da biblioteca, $2^{\circ}$ pavimento do bloco S. (a.a): Vista lateral $1^{\circ}$ aparelho, (a.b): Vista frontal $2^{\circ}$ aparelho, (b): Detalhe

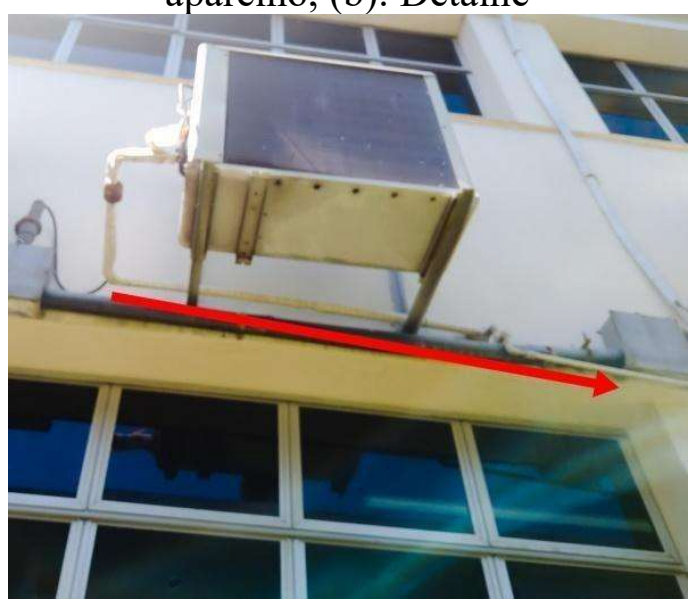

Fonte: Autor.

(a.a)

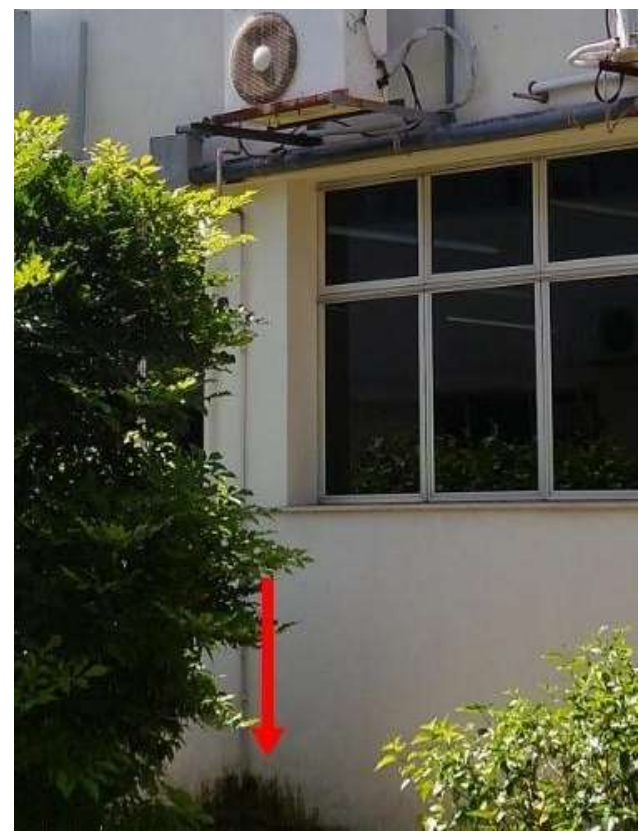

Fonte: Autor.

(a.b) 


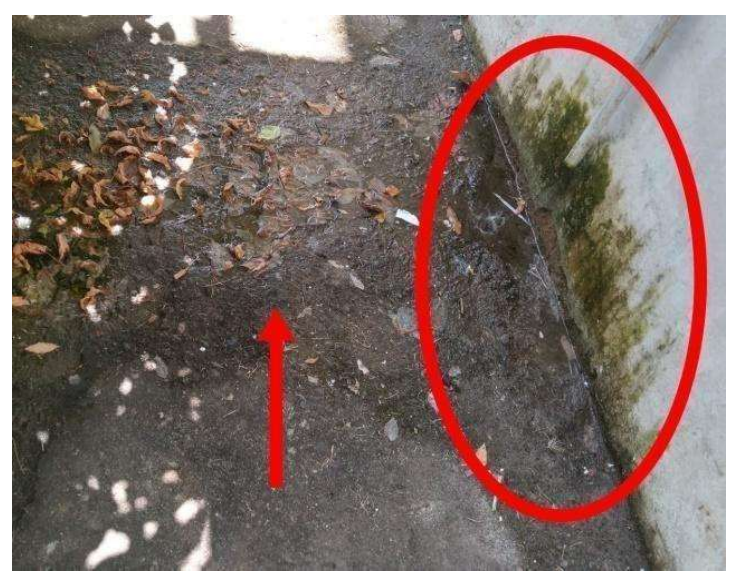

Fonte: Autor.

(b)

A manifestação patológica é de grau alto e do tipo 3: manchas, abrasão, empoçamento, lodo. Um cano recolhe a água condensada do $1^{\circ}$ e $2^{\circ}$ aparelhos e a despeja na calçada (figura 9b). A água cai na calçada, gerando abrasão, lodo e um grande empoçamento, que respinga na parede, afetando com lodo e abrasão a camada de revestimento rente ao chão.

Figura 10: $1^{\circ}$ ar-condicionado do laboratório de pesquisa de química, $2^{\circ}$ pavimento do bloco E. (a): Vista frontal,

(b): Vista do chão, abaixo do ar.

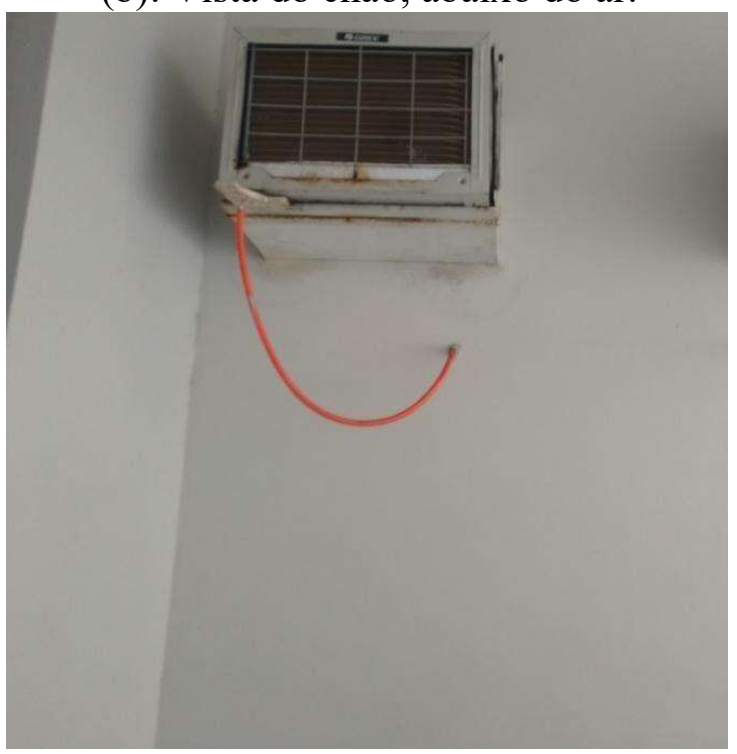

Fonte: Autor.

(a)

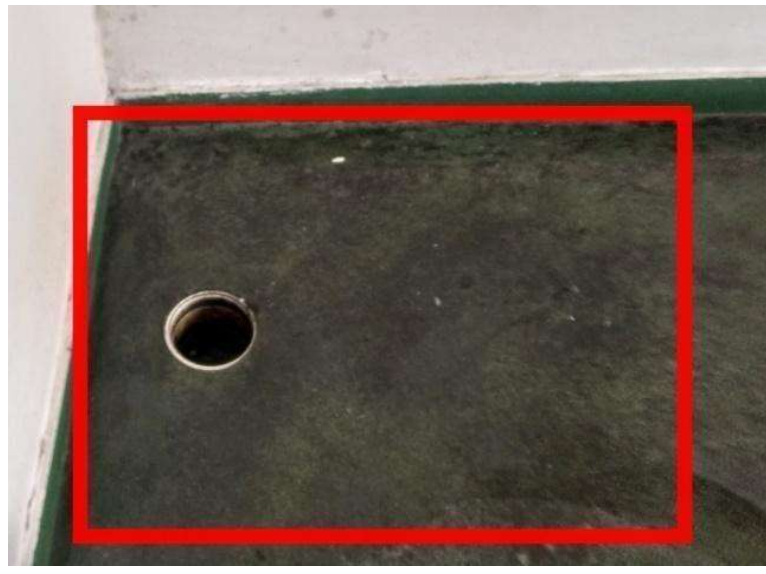

Fonte: Autor.

(b)

Foi identificada nessa área, a existência de sistema de drenagem ineficiente, tendo em vista a existência de um vazamento na parte externa, que dá para o corredor do bloco G, segundo pavimento. As ocorrências são de grau médio e do tipo 3: manchamento, abrasão, empoçamento, lodo. A água cai nesse canto do corredor, gerando uma leve abrasão e um grande acúmulo de água que levou ao surgimento de lodo no piso. As manchas escuras na figura $10 \mathrm{~b}$, provenientes do lodo, mostram que, além dos problemas construtivos, há risco de queda dos usuários.

Figura 11: Sala de preparo de microbiologia, $2^{\circ}$ pavimento do bloco $\mathrm{E}$.

(a): Vista frontal, (b): Detalhe

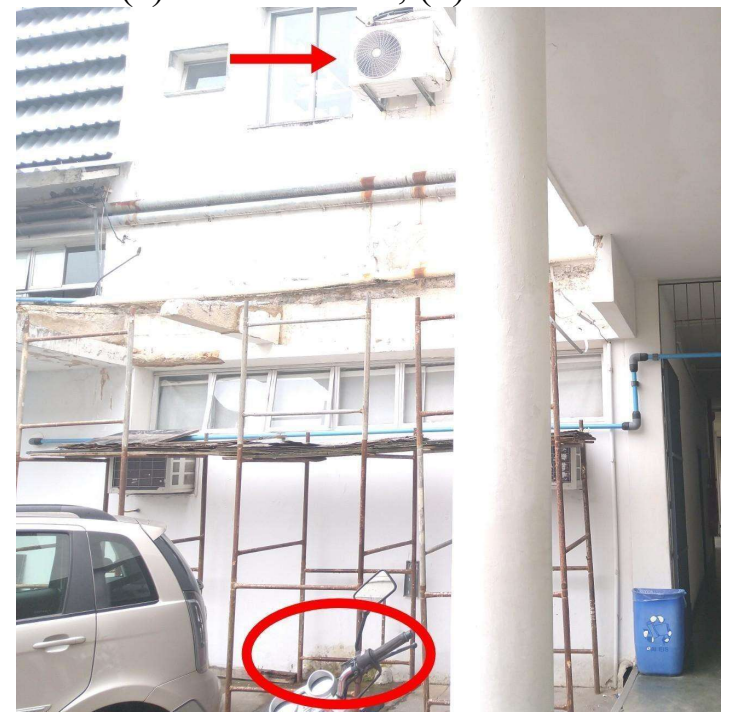

Fonte: Autor.

(a) 


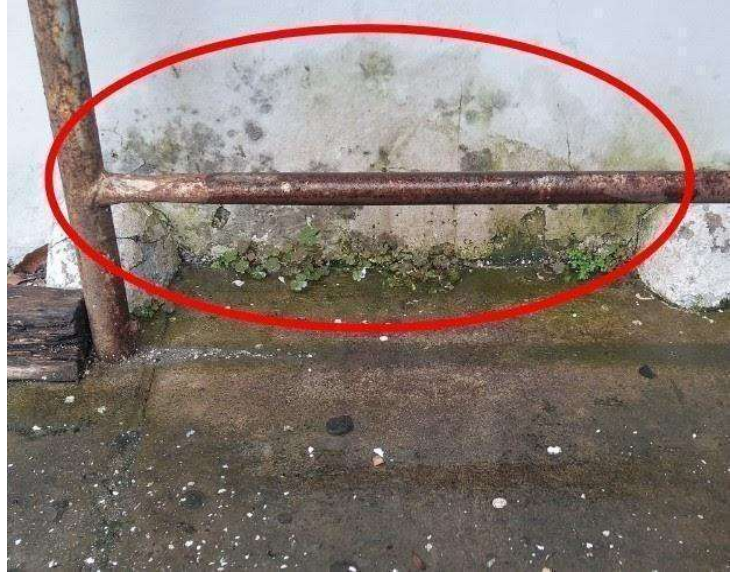

Fonte: Autor.

(b)

Os problemas são de grau alto e tipo 4: manchas, bolhas, lodo, empoçamento, abrasão, descascamento. Nesse local, a água vaza e cai na calçada gerando abrasão, empoçamento e lodo. Além disso, a água respinga na parede, onde foram detectadas as manifestações patológicas mais graves, que são manchas, bolhas, lodo e descascamento.

Figura 12: $1^{\circ}$ aparelho da sala de informática $2,2^{\circ}$ pavimento do bloco

B. (a): Vista lateral, (b): Detalhe

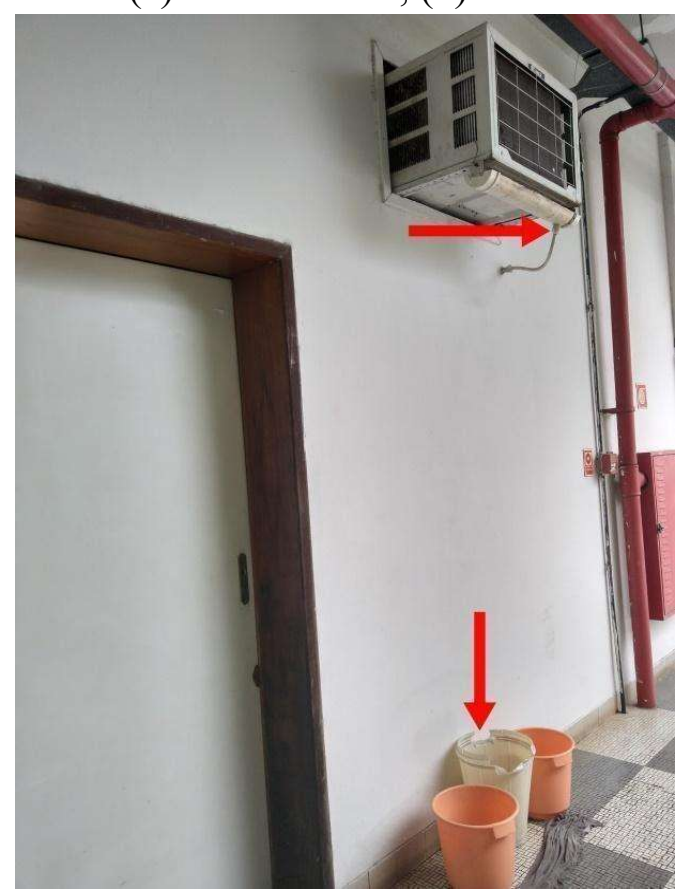

Fonte: Autor.

(a)

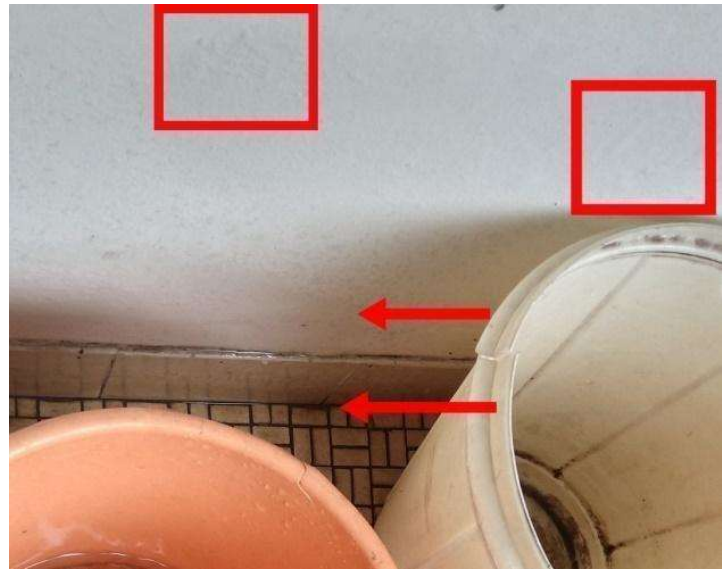

Fonte: Autor.

(b)

As manifestações patológicas da figura 12 são de grau alto e tipo 5: manchas, bolhas, empoçamento, abrasão. $\mathrm{O}$ aparelho possui sistema de drenagem, porém constatou-se um vazamento no dreno, de modo que o fluido cai no corredor, e ocasiona lodo no rejunte do chão, uma leve abrasão e um empoçamento considerável. Foi inclusive improvisada uma contenção com baldes para evitar o acúmulo de água, que respinga na parede, formando bolhas (detalhe da figura 12b), manchas e lodo em cima do rodapé.

Cabe salientar que o bloco Q não apresentou manifestações patológicas, tendo em vista que havia passado por uma reforma recente.

\subsection{QUANTITATIVO DAS MANIFESTAÇÕES PATOLÓGICAS}

De posse das manifestações patológicas encontradas e agrupadas por tipos (conjuntos mais frequentes) foi possível quantificar essas anomalias de acordo com o que foi apresentado no quadro 2 da metodologia, originando assim o quadro 3 a seguir. 
Quadro 3: União das manifestações patológicas encontradas e a quantidade de aparelhos que possuem cada uma

\begin{tabular}{|c|c|c|}
\hline Tipo & Manifestação patológica & Quant. \\
\hline 1 & Manchas, bolhas. & 22 \\
\hline 2 & $\begin{array}{l}\text { Manchas, lodo, abrasão, } \\
\text { empoçamento, bolhas. }\end{array}$ & 20 \\
\hline 3 & $\begin{array}{l}\text { Manchas, lodo, } \\
\text { empoçamento, abrasão. }\end{array}$ & 17 \\
\hline 4 & $\begin{array}{l}\text { Manchas, bolhas, lodo, } \\
\text { empoçamento, abrasão, } \\
\text { descascamento. }\end{array}$ & 10 \\
\hline 5 & $\begin{array}{l}\text { Manchas, bolhas, } \\
\text { empoçamento, abrasão. }\end{array}$ & 4 \\
\hline 6 & $\begin{array}{l}\text { Manchas, lodo, } \\
\text { descascamento, } \\
\text { empoçamento, abrasão, } \\
\text { fissura, bolhas, } \\
\text { saponificação. }\end{array}$ & 3 \\
\hline 7 & Manchas, lodo. & 3 \\
\hline 8 & $\begin{array}{l}\text { Manchas, lodo, } \\
\text { descascamento, } \\
\text { empoçamento, abrasão, } \\
\text { saponificação, bolhas. }\end{array}$ & 3 \\
\hline 9 & $\begin{array}{l}\text { Manchas, lodo, abrasão, } \\
\text { descascamento, } \\
\text { empoçamento. }\end{array}$ & 3 \\
\hline 10 & Manchas, abrasão. & 2 \\
\hline 11 & Manchas, abrasão, lodo. & 2 \\
\hline 12 & Empoçamento, abrasão. & 2 \\
\hline 13 & $\begin{array}{l}\text { Manchas, bolhas, abrasão, } \\
\text { lodo. }\end{array}$ & 2 \\
\hline 14 & $\begin{array}{l}\text { Manchas, empoçamento, } \\
\text { bolhas, descascamento. }\end{array}$ & 2 \\
\hline 15 & $\begin{array}{l}\text { Manchas, bolhas, } \\
\text { descascamento. }\end{array}$ & 2 \\
\hline 16 & $\begin{array}{l}\text { Manchas, lodo, } \\
\text { empoçamento, abrasão, } \\
\text { bolhas, fissura. }\end{array}$ & 1 \\
\hline 17 & bolhas. & 1 \\
\hline 18 & Abrasão. & 1 \\
\hline Total & & 100 \\
\hline
\end{tabular}

Fonte: Autor
Conforme apresentado no quadro 3, pode-se constatar que os conjuntos de manifestações patológicas mais comuns foram as do tipo do 1 ao 5, onde aparecem de 4 a 22 vezes os conjuntos de manifestações patológicas, os outros apareceram por menos de 4 vezes. Os mais frequentes foram os tipos 1 e 2 , encontrados 22 e 20 vezes, respectivamente. As manchas apareceram em quase todos os casos, se configurando uma característica comum decorrente de umidade originada de aparelhos de climatização.

De posse dessa classificação das manifestações patológicas foi realizado um mapeamento dos aparelhos de arcondicionados nas plantas baixas dos 9 blocos vistoriados do Campus. Neste mapeamento, constam a localização de cada aparelho, o tipo e o conjunto de manifestações patológicas encontradas no quadro 3. A figura 6 a seguir mostra o mapeamento do bloco $G$, que foi selecionado como exemplo por ser o que possui maior número de aparelhos causadores de anomalias. 
Figura 6: Planta baixa do pavimento térreo e superior do bloco $\mathrm{G}$, contendo a localização dos aparelhos e o tipo de manifestação patológica

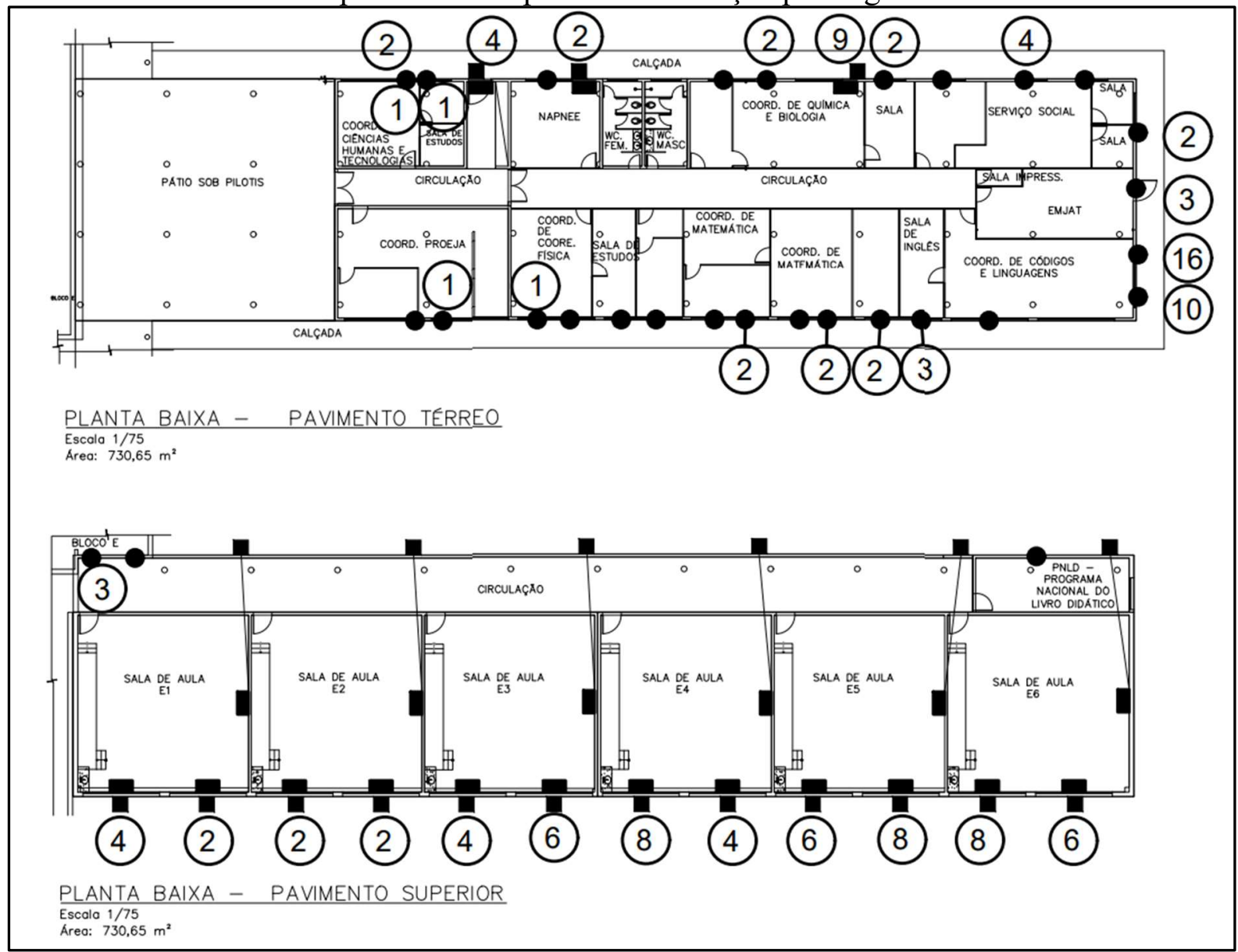

Fonte: Adaptada pelo autor

Com os dados obtidos a partir do mapeamento nas plantas baixas, foi montada a tabela 1 , trazendo a relação de cada bloco, apresentando as quantidades de: cada modelo de ar-condicionado, aparelhos que apresentaram manifestações patológicas, cada grau de degradação e manifestações patológicas mais comuns. 
Tabela 1: Resumo das manifestações patológicas nos blocos

\begin{tabular}{|c|c|c|c|c|c|}
\hline \multirow[b]{2}{*}{ Bloco } & \multicolumn{2}{|c|}{ Tipo } & \multirow[b]{2}{*}{$\begin{array}{l}\text { Quant. de } \\
\text { manifestações } \\
\text { patológicas. } \\
\text { Grau alto + } \\
\text { médio + baixo } \\
\quad=\text { total }\end{array}$} & \multirow[b]{2}{*}{$\begin{array}{c}\text { Percentual de } \\
\text { aparelhos que } \\
\text { ocasionaram } \\
\text { degradação } \\
\text { nas edificações } \\
(\%)\end{array}$} & \multirow[b]{2}{*}{$\begin{array}{c}\text { Manifestações patológicas } \\
\text { mais comuns (quant. de vezes } \\
\text { que aparece) }\end{array}$} \\
\hline & $\begin{array}{l}\text { Split } \\
\text { (quant. } \\
\text { com } \\
\text { manif./ } \\
\text { total) }\end{array}$ & $\begin{array}{c}\text { Janela } \\
\text { (quant. } \\
\text { com } \\
\text { manif./ } \\
\text { total) }\end{array}$ & & & \\
\hline B & $6 / 14$ & $7 / 28$ & $14+0+0=14$ & $31,00 \%$ & $\begin{array}{c}\text { Tipo } 1(7)-\text { manchas }(14) \mathrm{e} \\
\text { bolhas }(13)\end{array}$ \\
\hline $\mathrm{C}$ & $5 / 15$ & 0 & $5+0+0=5$ & $33,30 \%$ & $\begin{array}{c}\text { Tipo } 3(2) \text { e } 7(2)- \\
\text { manchas (4) e lodo (4) }\end{array}$ \\
\hline $\mathrm{D}$ & $6 / 6$ & 0 & $5+0+2=7$ & $100 \%$ & $\begin{array}{c}\text { Tipo } 2 \text { (4) - [manchas, lodo, } \\
\text { empoçamento e abrasão] (6), } \\
\text { bolhas(5) }\end{array}$ \\
\hline $\mathrm{E}$ & $8 / 20$ & $12 / 38$ & $16+4+2=22$ & $34,50 \%$ & $\begin{array}{c}\text { Tipo } 1(10) \text { - manchas }(21), \\
\text { bolhas (16), abrasão (10), lodo } \\
(8), \text { empoçamento }(8) .\end{array}$ \\
\hline G & $15 / 21$ & $15 / 26$ & $26+0+5=31$ & $63,80 \%$ & $\begin{array}{l}\text { Tipo } 2 \text { (11) e } 4 \text { (5) - manchas } \\
\text { (31), abrasão (27), bolhas (23), } \\
\text { lodo (26), empoçamento (26). }\end{array}$ \\
\hline Q & $0 / 1$ & 0 & 0 & $0 \%$ & 0 \\
\hline $\mathrm{R}$ & $1 / 12$ & 0 & $1+0+0=1$ & $8,30 \%$ & $\begin{array}{l}\text { Tipo } 3 \text { (1) - [manchas, lodo, } \\
\text { empoçamento, abrasão] (1). }\end{array}$ \\
\hline $\mathrm{S}$ & $17 / 19$ & $4 / 8$ & $15+2+1=18$ & $77,80 \%$ & $\begin{array}{c}\text { Tipo } 2 \text { (6) e } 3 \text { (6) - [manchas, } \\
\text { abrasão] (17), [lodo, } \\
\text { empoçamento] (15). }\end{array}$ \\
\hline $\mathrm{Y}$ & 0 & $1 / 6$ & $1+0+1=2$ & $16,70 \%$ & $\begin{array}{c}\text { Tipos } 3(1) \text { e } 14 \text { (1) - [manchas, } \\
\text { Abrasão, empoçamento] (2) }\end{array}$ \\
\hline Total & $58 / 107$ & $39 / 106$ & $84+5+11=100$ & $45,35 \%$ & $\begin{array}{l}\text { Tipo } 1 \text { (22), } 2 \text { (20) e } 3(17) \text { - } \\
\text { manchas }(91) \text {, abrasão (69), } \\
\text { bolhas }(66) .\end{array}$ \\
\hline
\end{tabular}

Fonte: Autor.

A partir da tabela 1 foi constatado que o número de tipos de manifestações patológicas é maior do que a quantidade de aparelhos que geram problemas, isso ocorre porque em 7 deles há presença de anomalias tanto na parte externa quanto na parte interna, assim um mesmo ar-condicionado possui 2 tipos de manifestações patológicas.

Cabe destacar que uma mesma anomalia pode ser originada a partir de 2 aparelhos, bastando os mesmos estarem ligados a um único tubo de drenagem. Tal fato ocorreu em 4 casos.

Observa-se que $97(45,33 \%)$ dos 214 aparelhos geram manifestações patológicas, ou seja, quase metade, conforme a tabela 1. Desses 97 de aparelhos que causaram problemas, somou-se 7 e subtraiu-se 4, o que resultou em 100 manifestações patológicas.

A quantidade de aparelhos split e de janela são quase a mesma, porém constatouse que o modelo split foi o que ocasionou 
mais problemas, sendo $58(59,80 \%$ das unidades com problema), enquanto que o de janela foram $39(40,20 \%$ das unidades com problema).

Com relação aos blocos, os $\mathrm{G}, \mathrm{S}$ e $\mathrm{E}$ foram os que apresentaram os maiores índices de ar-condicionados com manifestações patológicas, sendo 30 $(63,80 \%), 21(77,80 \%)$ e $20(34,50 \%)$ unidades, respectivamente. Os demais blocos apresentaram um índice menor de manifestações patológicas, menos de 15 unidades cada, como mostra a tabela 1 .

Foi realizado também outro levantamento mostrando a frequência em que cada anomalia aparece nos arcondicionados, como mostra a tabela 2.

Tabela 2: Frequência em que cada manifestação patológica aparece

\begin{tabular}{l|c}
$\begin{array}{c}\text { Manifestação } \\
\text { patológica }\end{array}$ & $\begin{array}{c}\text { Quantidade de } \\
\text { aparelhos em } \\
\text { que aparecem as } \\
\text { manifestações } \\
\text { patológicas }\end{array}$ \\
\hline Manchas & 91 \\
\hline Abrasão & 69 \\
\hline Bolhas & 66 \\
\hline Empoçamento & 63 \\
\hline Lodo & 62 \\
\hline Descascamento & 22 \\
\hline Saponificação & 6 \\
\hline Fissura & 4 \\
\hline
\end{tabular}

Fonte: Autor.

A anomalia que ocorreu com maior frequência foi a manchas, presente em 91 das 100 manifestações patológicas, ou seja, em quase todas. Em seguida, veio a abrasão (69), bolhas (66), empoçamento (63) e lodo (62). As outras 3 apareceram com baixa frequência, descascamento surgiu em 22, saponificação em 6 e fissura em 4 tipos, como apresentado na tabela 2 .
Com os dados referentes ao grau de manifestações patológicas encontradas (alto, médio, baixo e sem manifestações patológicas), pode-se gerar o gráfico apresentado na figura 13.

Figura 13: Percentual do grau de manifestações patológicas

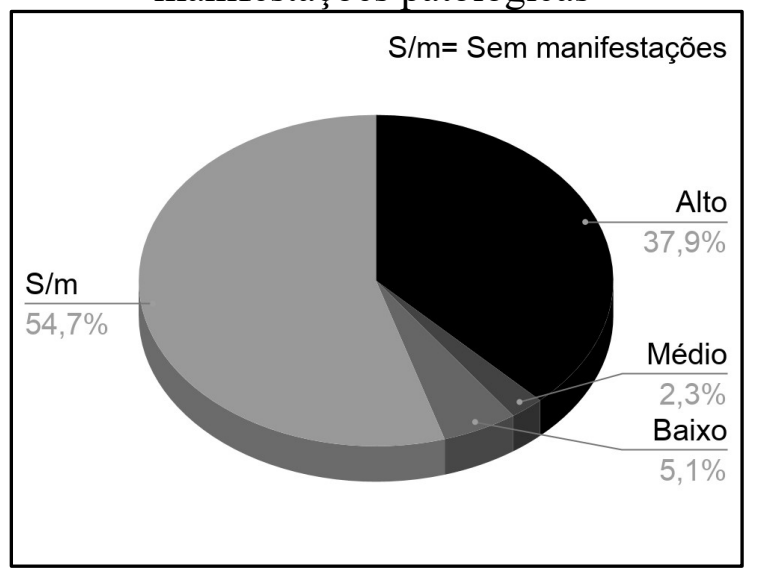

Fonte: Autor

Nos blocos, com exceção do bloco Y, o grau de degradação que prevaleceu foi o alto e, com relação ao total, ele representou 37,90\% dos aparelhos com problemas, enquanto que os de grau médio foram $2,34 \%$ e de grau baixo 5,14\%, como mostra a figura 13. Em relação aos 97 aparelhos com problemas, 83,50\% deles apresentaram manifestações patológicas de grau alto, $5,15 \%$ de grau médio e $11,35 \%$ de grau baixo.

Dentre os aparelhos que não geram problemas, $32(14,95 \%)$ deles não apresentam sistema de drenagem, o que os tornam potenciais causadores de manifestações patológicas futuras.

\section{CONCLUSÕES}

Neste trabalho foi possível identificar que as manifestações patológicas localizadas nas proximidades dos aparelhos de ar-condicionados da edificação do IFES, Campus Vitória, são em sua maioria efetivamente originárias desses aparelhos.

Foi constatado que 97 (45,33\%) dos 214 ar-condicionados são causadores de manifestações patológicas, sendo 82 
$(37,90 \%)$ deles de alto índice de degradação. Essa é uma quantidade muito elevada e, considerando que a grande maioria ocasiona um alto grau de degradação, entende-se que os problemas ocasionados pelos aparelhos são significativos. Tais problemas tomam grandes proporções e podem comprometer a estrutura da edificação, além de afetá-la no âmbito da estética, segurança e economia.

Ao final dessa pesquisa, sugere-se que os problemas levantados sejam estudados com profundidade, resultando em ações que atenuem ou solucionem as situações detectadas, proporcionando uma melhora visual, maior durabilidade da edificação e segurança para os usuários que frequentam as dependências do Ifes.

\section{AGRADECIMENTOS}

Ao Instituto Federal do Espírito Santo (Ifes), Campus Vitória, por tornar este estudo possível.

\section{REFERÊNCIAS}

ASSOCIAÇÃO BRASILEIRA DE NORMAS TÉCNICAS. NBR 15575:

Edificações habitacionais -

Desempenho. Parte 3: Requisitos para

os sistemas de pisos. Rio de Janeiro, 2013.

AMORETTI, Ana Maria; KOZLOSKI, Cássia Laire; PEREIRA, Niana; DE LIMA, Rogério Antocheves.

Manifestações patológicas na biblioteca central da universidade federal de Santa Maria - RS. In: Anais do congresso brasileiro de patologia das construções CBPAT 2020, 15 a 17 de abril em Fortaleza. Ceará 2020, p.3416-3426.

AYUSO, Manuel J. Carretero; CANSADO, Alberto Moreno; BRITO, Jorge. Study of the prevalence of critical and conflict-prone points in facades.
Engineering Failure Analysis, v. 75, p. 15-25, 2016.

BEZERRA, José E. A.; LIMA, Andrélia de F.; CABRAL, Antônio E. B.; OSHIRO, Angel. Análise das condições do concreto do canal de retenção de areia de uma estação de pré-condicionamento de esgoto. In: Anais do congresso brasileiro de patologia das construções CBPAT 2020, 15 a 17 de abril em Fortaleza. Ceará 2020, p. 794-804.

CORSINI, R. Trinca ou fissura?. São Paulo: Téchne. 160, p., jul. de 2010. Disponível em: <http://techne.pini.com.br/ engenharia-civil/160/trinca-ou-fissuracomo-se-originam-quais-os-tipos-2854881.aspx>. Acesso em 06 dez. 2019.

FERREIRA Gomes, Júlio Roberto; DE OLIVEIRA Quesado Filho, Nelson.

Fissuras em edificações públicas antigas na cidade de Fortaleza-CE: exame das causas e soluções. In: Anais do congresso brasileiro de patologia das construções CBPAT 2020, 15 a 17 de abril em Fortaleza. Ceará 2020, p. 2583-2593.

FRANÇA, Alessandra A. V.; MARCONDES, Carlos Gustavo N.; ROCHA, Francielle C. Patologia das construções: uma especialidade na engenharia civil. 2011. 10f. Programa de Pós-graduação (Pós-graduação em Construção Civil). UFPR, Paraná, 2011.

FREITAS, Ingrid; JÁCOME, Camila; MAIA, Gabriela. Identificação e análise das manifestações patológicas em edificações históricas localizadas no município de Aracati - CE. In: Anais do congresso brasileiro de patologia das construções - CBPAT 2020, 15 a 17 de abril em Fortaleza. Ceará 2020, p.33173325 .

GOOGLE Maps: Ifes Campus Vitória. Disponível em: www.google.com.br/maps. Acesso em: jul. 2020. 
MARTINS, Wiliam Silva; MENDES, MARCUS Vinícius A. Silva; PITALUGA, Douglas Pereira da Silva. Procedimento para inspeção e diagnóstico de patologias provenientes de infiltração e umidade em edificações: estudo de caso no instituto federal de goiás - câmpus Goiânia. In: Anais do congresso brasileiro de patologia das construções - CBPAT 2020, 15 a 17 de abril em Fortaleza. Ceará 2020, p.1856-1867.

OLIVEIRA, G. J.; DIAS, R. A; BORBA JR, J. C.; DUARTE, L. N. Patologia causada por umidade: estudo de caso no Campus Alto Paraopeba. In: Anais do congresso brasileiro de patologia das construções - CBPAT 2016, 18 a 20 de abril em Belém do Pará. Ouro Branco-MG, abril 2016, p.1855-1866.

OLIVEIRA, Valéria; ZANOLLA, Ieda; OLIVEIRA, Franciele; PEIXOTO, Maria Eliana; MELO, Rorennychollas; GRINGS, Kátia. Agentes de degradação relacionados aos projetos de engenharia. In: Anais do congresso brasileiro de patologia das construções - CBPAT 2020, 15 a 17 de abril em Fortaleza. Ceará 2020, p. 1280-1291.

PEREIRA, Clara; SILVA, Ana; BRITO, Jorge, SILVESTRE, José D. Urgency of repair of building elements: Prediction and influencing factors in faça de renders.

Construction and Building Materials, v. 249, p. 1-16, 2020.

SACHS, A. Tratamento intensivo. São Paulo: Téchne. 220, p. 40-44, jul. 2015.

SILVA, Ana Cássia, FALCÃO, Natacha; MARTINS, Ully. Manifestações patológicas em habitações de interesse social: estudo de caso em conjunto habitacional no município de Beberibe/CE. In: Anais do congresso brasileiro de patologia das construções -
CBPAT 2020, 15 a 17 de abril em Fortaleza. Ceará 2020, p. 3753-3764. SOUZA, Vicente C. M.; RIPPER, Thomaz. Patologia, recuperação e reforço de estruturas de concreto. 1a edição, $5^{\mathrm{a}}$ tiragem, abril 2009. São Paulo: Pini, 1998, 257 f.

SUETH, José C. R.; MELLO, José C.; DEORCE, Mariluza S.; NUNES Reginaldo F. A trajetória dos 100 dos eternos titãs: da escola de aprendizes artífices do Espírito Santo. 176 p. Instituto Federal de Educação, Ciência e Tecnologia do Espírito Santo. Vitória, 2009.

VEDOVA, Adão J. B. Imagens históricas da década de 1930/40 retratando a construção da nova sede da Escola Técnica de Vitória (atual Ifes Campus Vitória) no bairro de Jucutuquara. 23 set. 2020. Facebook: IFES - Campus Vitória. Disponível em: https://www.facebook.com/groups/378552 815676304/?ref=share. Acesso em: nov. 2020. 